\title{
APL Differentiation Syndrome
}

National Cancer Institute

\section{Source}

National Cancer Institute. APL Differentiation Syndrome. NCI Thesaurus. Code C78597.

A syndrome observed in patients with acute promyelocytic leukemia treated with all-trans retinoic acid. It is characterized by weight gain, dyspnea, pleural and pericardial effusions, leukocytosis, and renal failure. 